\section{Valor y dignidad del individuo en el pensamiento político de Hegel}

The Value and Dignity of the Individual in Hegel's Political Thought

\author{
Héctor Ferreiro
}

\section{RESUMEN}

La concepción social y política de Hegel ha sido no pocas veces interpretada como una defensa de un estatismo autoritario en el que no hay lugar alguno para el individualismo moderno. En el presente artículo se defiende, por el contrario, la tesis que la toma de conciencia por parte del individuo de su valor y dignidad es la conclusión de la antropología filosófica de Hegel y, con ello, el principio y fundamento de toda su filosofía política. El valor y dignidad del individuo radican para Hegel, más precisamente, en su libertad de autodeterminación. Las estructuras de interrelación personal que Hegel desarrolla en la filosofía del derecho no son, pues, sino aquellas que ofrecen el marco general para el ejercicio de la libertad de autodeterminación de cada individuo, es decir, en otros términos, las que garantizan la formación e interacción de agentes humanos autónomos. La libertad como capacidad de autodeterminación no implica, sin embargo, que la meta del obrar deba ser que cada individuo haga lo que quiera. Para Hegel, el bien común no es un resultado necesario de la suma total de las acciones de los individuos destinadas a lograr su respectivo bien privado; precisamente por esto, el bien común debe ser un objetivo en sí mismo y debe haber una entidad específica que lo tenga como su meta, a saber: el Estado. El sentido mismo del Estado es para Hegel, en efecto, asegurar que todos y cada uno de los individuos que conforman la sociedad se convierta en un agente autónomo y pueda ejercer su capacidad de autodeterminación. Palabras clave: Hegel; Filosofía política; Teorías de la libertad; Individualismo; Totalitarismo

\section{ABSTRACT}

Hegel's social and political thought has been often been interpreted as a defense of authoritarian statism against modern individualism. In this paper I claim, on the contrary, that the value and dignity of the individual is the conclusion of Hegel's philosophical anthropology and, thus, the principle and foundation of his entire political philosophy. The value and dignity of the individual rely, more precisely, on her freedom of selfdetermination. The different forms of personal interaction that Hegel develops in his philosophy of Right are thus those that offer the condition of possibility for the exercise of the freedom of self-determination of each individual. Freedom as the capacity to determine oneself does not imply, however, that the goal of human action should be that each individual does whatever she wants. Common good is not the necessary result of the sum of all the actions of the individuals in order to obtain their private well-being; precisely because that is not the case, the common good must be a goal in itself and there must exist a specific organization that takes it as its own goal, namely the State. Indeed, the whole meaning of the State is for Hegel to guarantee that all individuals in society become effectively autonomous agents and can exert their capacity of selfdetermination.

Keywords: Hegel; Political Philosophy; Theories of Freedom; Individualism; Totalitarianism

\section{INFORMACIÓN}

http://doi.org/10.46652/resistances.v2i4.73 ISSN 2737-6222 |

Vol. 2 No. 4, 2021, e21073

Quito, Ecuador

Enviado: noviembre 02, 2021 Aceptado: diciembre 30, 2021 Publicado: enero 10, 2022 Publicación continua Sección dossier | Peer Reviewed

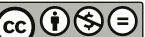

open $\bigcirc$ access

AUTOR

Héctor Ferreiro Consejo Nacional de Investigaciones Científicas y Técnicas - Argentina hferreiro@conicet.gov.ar

Conflicto de intereses

El autor declara que no existe conflicto de interés posible.

Financiamiento

No existió asistencia financiera de partes externas al presente artículo.

Agradecimiento

Agradezco a la revista Resistances. Journal of the Philosophy of History, por la invitación a co-editar el dossier "Legal, economic, and political in Hegel's Philosophy of Right". Nota

Este es un trabajo inédito que no pertenece a ningún proyecto financiado.

PUBLISHER 


\section{La leyenda negra del estatismo hegeliano}

La crítica a la filosofía política de Hegel como un intento de legitimación teórica del estatismo autoritario en detrimento de los individuos se remonta a los tiempos del propio Hegel. En efecto, ya en 1821, es decir, en el mismo año en que aparecieron publicadas las Líneas fundamentales de la filosofía del derecho, el filósofo Jakob Friedrich Fries criticó a Hegel en ese sentido (Nicolin, 1970, p. 221). También Marx consideró a Hegel un defensor del statu quo de la Prusia reaccionaria de su época y rechazó lo que creía era el potencial autoritario de su concepción política. En el así llamado Manuscrito de Kreuznach (1843), conocido también como Crítica de la filosofía del derecho de Hegel [Zur Kritik der Hegelschen Rechtsphilosophie], Marx sostiene que "Hegel parte del Estado y convierte al hombre en el Estado subjetivado; la democracia parte del hombre y convierte al Estado en el hombre objetivado. [...] En todos los Estados que se diferencian de la democracia el Estado, la Ley, la Constitución son lo dominante[.] [...] En la democracia, la Constitución, la Ley, el Estado mismo es solo una autodeterminación del pueblo" (Marx, 1981, pp. 231-232). Publicado en 1857, Hegel y su tiempo, de Rudolf Haym, se convirtió a partir de la segunda mitad del siglo XIX en la principal obra de referencia de quienes querían ver en Hegel al filosófo de la Restauración y de la concepción antiliberal del Estado (Haym, 1857). Apenas terminada la Primera Guerra Mundial, el teórico británico del liberalismo Leonard T. Hobhouse insistió en The Metaphysical Theory of the State en la misma lectura de la filosofía política de Hegel. Hobhouse achaca a Hegel el endiosamiento del Estado en detrimento de los individuos (1918, pp. 6, 20, 23-24, 38, 68, 87, 96-97, 100-101, 134-136) y lo acusa, sobre esa base, de ser uno de los responsables intelectuales de la Gran Guerra: “[C]uando es convertido en una entidad superior e indiferente a los individuos que lo componen, el Estado deviene un falso dios, y su adoración la abominación de la desolación, como puede verse en Ypres o en el Somme" (1918, p. 136).

La imagen que Hobhouse construye de Hegel y su pensamiento político tuvo una gran repercusión en los países de habla inglesa (Goodfield, 2017, pp. 297-299). En las décadas siguientes siguen en mayor o menor medida sus pasos, entre otros, los filósofos políticos estadounidenses George Sabine y Sidney Hook (Sabine 1932; Sabine, 1937; Hook, 1936). Hook sostiene que "la glorificación de la Iglesia cede paso a la glorificación del Estado: se comienza con el Génesis y se termina con Hegel” (1936, p. 84) y repite, años más tarde: “Hegel glorificó al Estado y cantó los usos de la guerra" (Hook, 1965, p. 53). En una misma línea con esta tradición, en el año 1945 aparece La sociedad abierta y sus enemigos, de Karl Popper. Popper, quien se convertiría con el tiempo en "el indiscutido heredero de la crítica de Haym" (Goodfield, 2017, p. 301), habla allí de "la platonizante adoración hegeliana del Estado" y afirma que para Hegel “el Estado es todo y el individuo nada” (Popper, 1945, p. 29). Popper hace también suya la acusación que Hobhouse había dirigido contra Hegel en 1918, a saber: ser uno de los mentores intelectuales de la guerra, pero esta vez, en 1945, Popper se refiere también a la Segunda Guerra Mundial (1945, p. 30; 1994, pp. 158-159). Al año siguiente de su publicación, Bertrand Russell calificó a La sociedad abierta y sus enemigos de "obra de relevancia de primer orden, que debería ser extensamente leída por su crítica magistral a los enemigos de la democracia. [...] Su análisis de Hegel es letal 
y muy competente" (Grattan-Guinness, 1992, pp. 10-11). El vínculo que Popper establece entre la filosofía política de Hegel y el totalitarismo convergía en la práctica con la lectura que habían desarrollado intelectuales católicos europeos, sobre todo franceses, el más conspicuo de los cuales era Jacques Maritain, quien había afirmado en Humanismo integral, publicado en 1936, que el individuo "está maduro para abdicar en provecho del hombre colectivo, de esa gran figura histórica de la humanidad cuya teología ha elaborado Hegel” (1936, p. 38). E insistía algunos años más tarde, en Hombre y Estado (1951), que Hegel es "el profeta y teólogo del divinizado Estado totalitario" (1951, p. 17). François de Menthon, Fiscal principal por la República Francesa en el Juicio de Nuremberg y amigo personal de Maritain, aprovecha la ocasión de su discurso inaugural en el Juicio, el 17 de enero de 1946, para afirmar que "el sistema estatal totalitario tiene en Alemania raíces antiguas. La desaparición del hombre en el Estado fue un deseo de Hegel, quien escribió que los individuos desaparecen ante la sustancia universal, el espíritu del pueblo o del Estado" (Internationaler Militärgerichtshof Nürnberg, 1994, pp. 425-426). También en 1946 el filósofo neokantiano Ernst Cassirer sostiene que Hegel "consideró a los individuos como marionetas en el gran show de títeres de la historia universal. Según Hegel, el autor y dramaturgo del drama histórico es la Idea: los individuos no son más que agentes del 'espíritu del mundo"” (1946, p. 269). En 1969, Adorno traza un expreso paralelo entre la concepción hegeliana del espíritu como totalidad y la disolución del individuo en el totalitarismo del partido único (1986, p. 199). Por último -aunque sin pretender en modo alguno haber ofrecido aquí una nómina exhaustiva de los detractores de la filosofía política de Hegel-, Hubert Kiesewetter publica en 1974, bajo la influencia personal directa de Popper, De Hegel a Hitler, obra que sigue siendo todavía hoy el intento más detallado de hacer plausible el vínculo entre la concepción política de Hegel y el nazismo (Kiesewetter, 1974; 1995; Jouanjan, 1997; Jouanjan, 2002; Hürstel, 2010).

Como puede verse, la remisión a Hegel en el contexto de la búsqueda de precursores intelectuales de los totalitarismos del siglo XX ha sido un lugar común profusamente visitado. Aunque puede reclamar para sí una extensa tradición, la lectura del ideario político de Hegel como una operación de legitimación de un estatismo radicalizado que asfixia los derechos de los individuos adolece, sin embargo, de una seria debilidad exegética. Salvo alguna excepción -Adorno podría ser considerado una de ellas-, los autores que han defendido dicha lectura no han sido de hecho especialistas reconocidos en la obra de Hegel, sino más bien autores que se han acercado a la misma de forma externa y, en última instancia, superficial. La interpretación del pensamiento político de Hegel en clave estatista y autoritaria descansa en una lectura que se concentra exclusivamente en el papel que Hegel asigna al Estado en relación a las personas particulares y a sus vínculos mutuos en la familia y la sociedad, y olvida o ignora el rol específico que Hegel asigna a la vida política en el proceso total de autocomprensión de la libertad como esencia del ser humano. Dicha lectura busca legitimarse conceptualmente ante todo en la tesis hegeliana del Estado como un organismo que, en cuanto es "lo primero" [das Erste], se diferencia a sí mismo en la familia y la sociedad civil como sus propios miembros (Hegel, 2009, pp. 58 [\$46 Anm.], 200 [§256 Anm.], 205 [§259], 211 [\$267], 212 [\$269], 214 [§270 Anm.], 223 [\$271], 231 [\$278 Anm.], 234-235 [\$279 Anm.], 239 [\$286], 250-251 [\$302], 251 [\$303]). Ha sido una práctica común remitir en este contexto a una selección de pasajes aislados en la obra de Hegel en los que el 
Estado es caracterizado con una terminología de sesgo religioso (véase, por ejemplo, Hobhouse, 1918, pp. 6, 20, 87, 100-101 y Popper, 1945, p. 29), en concreto: “El Estado es la marcha de Dios en el mundo" (Hegel, 1970a, p. 403 [\$258 Zus.]); "el Estado es la voluntad divina como espíritu presente que se despliega en figura real y organización de un mundo" (Hegel, 2009, p. 214 [\$270 Anm.]) y "hay que venerar al Estado como algo divino terrenal [Irdisch-Göttliches]" (Hegel, 1970a, p. 434 [\$272 Zus.]). Vincularlo con Dios y caracterizarlo como “divino" parece ser, a primera vista, un recurso retórico que Hegel habría usado para manifestar una valoración extrema de lo estatal en detrimento de lo individual. Sin embargo, semejante interpretación descansa en una simple asociación de ideas sobre la base del uso cotidiano de los términos "Dios" y "divino", y no en un análisis de lo que el propio Hegel entendió bajo esos términos. Para Hegel, el Estado y, más en general, la vida social de los individuos no constituye lo absoluto; por el contrario, se trata expresamente de formas del espíritu finito (Hegel, 2011, p. 941 [Enz §386 Zus.]), que deben ser superadas por la explicitación de lo absoluto, lo cual no acontece en la vida social y estatal misma, sino recién en las prácticas culturales del arte, la religión y la filosofía. Pero incluso el concepto tradicional de Dios tal como lo conciben las religiones es todavía una concepción inexacta, por meramente metafórica, de lo absoluto. En la filosofía de Hegel, lo absoluto es un modo de referirse al carácter ilimitado de la razón humana, el cual es explicitado como corresponde solo por la filosofía. "Dios” y “divino" no significan para Hegel, pues, lo mismo que en el lenguaje habitual; son, en rigor, solamente una forma figurativa de concebir la unidad entre la racionalidad humana y el mundo, un modo alegórico de describir la unidad ilimitada por fuera que existe entre la estructura cognitiva del sujeto y el mundo que le resulta específico a ese tipo de estructura cognitiva. “Absoluto” está lejos de significar en el pensamiento de Hegel el Dios de las religiones, esto es, un ser personal trascendente, frente a cuya grandeza y poder infinitos los individuos resultan, en último análisis, insignificantes.

El modo de pensar propio de la religión tiene a ojos de Hegel una lógica de desarrollo interna según la cual su carácter figurativo va siendo depurado hasta llegar a las concepciones máximamente universales de la ciencia y la filosofía. El último estadio del discurso religioso lo constituye la religión cristiana con la tesis de la Encarnación de Dios. Para Hegel, la idea de que Dios se convierta en un ser humano es el modo simbólico de sostener que, por un lado, lo divino es humano -esta idea está en la base de la famosa tesis de Feuerbach que el secreto de la teología es la antropología (Feuerbach, 2006, pp. 7, 18, 352, 443)-, pero también, por el otro, que lo humano es divino; que Dios se haga humano es para Hegel, en efecto, el modo de decir propio del pensar religioso que cada ser humano tiene un valor intocable, precisamente por haber sido creado por Dios y ser objeto de su amor y sacrificio (Feuerbach, 2006, p. 20; Stewart, 2018, p. 293). El ser humano no tiene valor porque tenga riqueza o poder o pertenezca a un grupo determinado dotado de privilegios, sino que, en cuanto creatura de Dios y objeto de su amor, tiene valor como tal y, en verdad, por ello mismo, un valor infinito. Esta es justamente la tesis con la que Hegel cierra su entera filosofía del espíritu subjetivo, esto es, de lo que puede se caracterizado como su antropología filosófica en sentido amplio: 
Partes enteras del mundo, África y el Oriente, no han tenido nunca esta idea [= la idea de la libertad, H.F.] y todavía no la tienen; los griegos y los romanos, Platón y Aristóteles no la han tenido, tampoco los estoicos; por el contrario, solo supieron que el ser humano es efectivamente libre por nacimiento (en cuanto ciudadano ateniense, espartano, etc.) o por fuerza de carácter, por educación, por la filosofía (el sabio es libre incluso como esclavo y en cadenas). Esta idea ha venido al mundo a través del cristianismo, según el cual el individuo tiene en cuanto tal un valor infinito [das Individuum als solches einen unendlichen Wert hat] en la medida en que es objeto y fin del amor de Dios, que está destinado a tener su relación absoluta con Dios como espíritu y a tener este espíritu morando en su interior, esto es, que el ser humano está en sí [an sich] destinado a la libertad suprema. (Hegel, 1992, p. 477 [Enz §482 Anm.]) [NB: Las cursivas son nuestras, H.F.].

\section{El ser humano como agente libre}

La toma de conciencia del valor y la dignidad (Hegel, 1970c, p. 227) de cada ser humano es en el Sistema de Hegel la conclusión final de la filosofía del espíritu subjetivo; en esa medida, es el fundamento de toda su filosofía política, la cual es, como el propio Hegel lo aclara, la realización de esa autoconciencia como un principio [Prinzip] todavía abstracto a ser desarrollado (Hegel, 1992, p. 477 [Enz §482 Anm.]; Hegel, 2009, p. 41 [§21 Anm.]). Las sucesivas figuras del espíritu objetivo, esto es, entre otras, las relaciones interpersonales en el matrimonio, en la interacción económica y en la vida intraestatal e interestatal deben ser para Hegel, en efecto, realizaciones de la naturaleza del ser humano en cuanto dotada de un valor y dignidad incondicionales.

Ahora bien, la caracterización del ser humano como una entidad que tiene valor infinito es una mera constatación, y no una explicación de por qué cada individuo tiene ese valor. Lo que para Hegel fundamenta el valor y la dignidad de la persona humana es su libertad. Pero, ¿qué entiende exactamente Hegel por "libertad"? El espíritu humano parte en su actividad de conocimiento de su propia naturalidad determinada inmediata, esto es, de su propia corporeidad afectada por el mundo con el que interactúa. Esta corporeidad implica, por un lado, las características naturales de cada persona, su particular constitución física y de carácter, su sexo, el grupo étnico y cultural al que pertenece y las características que Hegel cree están asociadas a ese grupo; por otro lado, implica también las determinaciones que afectan al sujeto como objetos de conocimiento y que en el proceso cognitivo van a ser reelaboradas por el mismo como cosas diferentes de él. Todo ser humano se encuentra con su propia particularidad determinada inmediatamente de tal o cual manera. A partir de ella va diferenciando qué le pertenece como su propio cuerpo, qué son determinaciones de su propia subjetividad individual y qué son objetos de un mundo diferente de ambos. Kant había establecido en el principio de la unidad sintética de la apercepción que el "yo pienso" debe acompañar a todas las representaciones que tiene el sujeto, porque, si no lo hiciera, esas representaciones -o, mejor aun, los contenidos de las mismas- no serían nada para él, es decir, el sujeto sería enteramente inconsciente de los contenidos representados; más claramente: todos los objetos que el individuo conoce pueden ser conocidos por él en la exacta medida en que se le dan en su propia subjetividad (Kant, 1998, p. 178 [KrV, B 131-132]). 
El ser humano no puede tomar conciencia de nada que no lo afecte en forma directa y que, al menos mediatamente, esté vinculado con lo que lo afecta de manera directa. En efecto, si bien no podemos percibir lo que sucede en la superficie de planetas de estrellas de otras galaxias, podemos a través de lo que percibimos llegar a desarrollar una teoría acerca de lo que sucede en esos planetas. Para Hegel, como para los empiristas, el sujeto cognoscente parte siempre de sus propias afecciones sensibles, pues no puede conocer nada que no lo afecte en su propio pensamiento; sin embargo, la mente humana, a diferencia de la mente del animal, puede reelaborar aquello que la determina, y puede hacerlo precisamente porque lo que la determina es una determinación de ella. Lo que determina al sujeto es el sujeto mismo en cuanto está determinado según ese algo. En la filosofía del espíritu subjetivo, Hegel expone el proceso mediante el cual el sujeto va poniéndose de manifiesto a sí mismo que las determinaciones que lo afectan al principio de modo inmediato como siendo en sí mismas son, en realidad, sus propias determinaciones. Explicitar que los contenidos que determinan al sujeto son sus propias determinaciones no significa, sin embargo, como ha sido a veces malentendido, que ellos sean "solo" determinaciones del sujeto, esto es, que no sean además cosas. Para Hegel, como antes lo había sido para Fichte, lo que determina al sujeto es una determinación tanto subjetiva (de lo contrario, el sujeto no tendría conciencia de ella) como objetiva. La subjetividad humana va tomando conciencia de su naturaleza, en la exacta medida en que va tomando conciencia de la unidad intrínseca e indisoluble entre lo que conoce y que eso que conoce es al mismo tiempo su propia determinación. Es esta unidad entre el objeto y el sujeto lo que Hegel, siguiendo también en esto a Fichte, concibe como "lo absoluto".

A medida que el sujeto va tomando conciencia de su unidad con el objeto, el objeto va perdiendo la forma unilateral de ser solamente en sí mismo y se va convirtiendo en una determinación del sujeto. Precisamente porque las determinaciones de las que es consciente son las suyas propias es que el sujeto humano puede modificarlas mediante su actividad. Así, por ejemplo, el sujeto puede elaborar a partir de lo que percibe una imagen de lo percibido, imagen que puede luego reproducir o re-concientizar en otro momento y lugar. El sujeto puede además asociar imágenes entre sí, subordinarlas unas a otras creando símbolos y signos y, finalmente, mediante el lenguaje, puede relacionar y mediar entre sí todas las determinaciones que conoce a través de juicios e inferencias, llegando con ello a comprender el mundo que al principio lo afectaba de manera inmediata como algo que era solamente en sí mismo. Todo esto el sujeto puede hacerlo porque tiene poder sobre su propia actividad y, en esa exacta medida, sobre las determinaciones de esa actividad. Los animales, por el contrario, si bien son capaces de reelaborar parcialmente las determinaciones que conocen, no pueden, por lo visto, explicitar que esas determinaciones que los afectan son las suyas propias, dado que en determinado punto permanecen paralizados en la forma del ser en sí mismo de las determinaciones de las que son conscientes, las cuales, en esa precisa medida, se les imponen y los determinan. En efecto, el animal actúa en reacción a emociones puntuales y espontáneas; el ser humano, en cambio, puede adelantarse a lo inmediato y predecir que, dado que eso pertenece a tal o cual tipo de objetos, se va a comportar de tal o cual manera. El sujeto humano no está, pues, hundido en lo que lo afecta de forma inmediata, sino que es libre respecto de ello, y lo es porque puede eliminar la mera forma del 
ser en sí mismo de lo que lo afecta y explicitar que es una determinación del propio sujeto. La quintaesencia de la libertad de la subjetividad humana descansa para Hegel justamente en esta capacidad de autodeterminarse en aquello que la determina. Que el sujeto pueda comprender lo que lo afecta es para Hegel la manifestación de que la subjetividad humana es libre. Si Descartes escribió “pienso, por lo tanto, existo", Hegel bien pudo escribir “comprendo, por lo tanto, soy libre": su tesis que la voluntad es la verdad [Wahrheit] de la inteligencia (Hegel, 1970a, p. 48 [\$4 Zus.]), o, lo que es lo mismo, que la voluntad resulta del proceso consumado del espíritu teórico, no significa sino justamente eso. El sujeto puede comprender lo que lo afecta, precisamente porque en esa afección puede mantenerse idéntico a sí mismo y re-determinar el contenido de la misma mediante su propia actividad. Pero, así como el pensamiento puede mantenerse idéntico a sí mismo en lo que lo afecta, también puede conservar su identidad consigo mismo respecto de sus propias afecciones inmediatas, esto es, respecto de sus sentimientos y pasiones -hambre, miedo, dolor, placer, etc.--, los cuales lo asaltan como si fueran algo externo a él, como si, a pesar de que son sus propios sentimientos y deseos, no fueran él mismo. En forma análoga a como es capaz de poner las determinaciones de los objetos externos como sus propias determinaciones, el sujeto también puede poner o explicitar como sus propias determinaciones las determinaciones inmediatas de sí mismo. Con esto, sus sentimientos, deseos e impulsos no lo mueven más como si fueran cosas que mueven a otra cosa.

El modo como Hegel concibe la relación entre la autoconciencia y su propias determinaciones, es decir, la capacidad que Hegel le adscribe al sujeto humano de resolverse mediante su elección por sus determinaciones, parecería ser vulnerable a la crítica que la libertad no es más que una ilusión. Kant había distinguido la libertad práctica respecto de la libertad trascendental. La libertad práctica, esto es, la capacidad del sujeto de resolverse no por aquello que está sintiendo en ese preciso momento y lugar, sino por metas universales o racionales, no es la libertad trascendental, es decir, no es la presunta capacidad del sujeto de iniciar de modo absoluto una serie causal a partir de sí mismo (Kant, 1998, pp. 621-622 [KrV, A 533-534/B 561562], 836-837 [KrV, A 803/B 831]). Para Kant, los contenidos universales determinan al sujeto en forma análoga a como lo determinan los contenidos sensibles. La capacidad de elegir entre distintas metas y resolverse por una de entre todas ellas por razones universales y no por su imposición espontánea no puede, según Kant, ser identificada con la capacidad de iniciar de manera absoluta una serie causal. Para Hegel, sin embargo, el discurso acerca de la "fuerza" de los contenidos por los cuales el sujeto sería determinado a obrar y, en esa medida, no sería libre, no es más que un modo de hablar metafórico que surge por la extrapolación al ámbito de las relaciones del sujeto con sus propias determinaciones de las categorías con las que el sujeto analiza las cosas que le son externas. Hegel defiende una concepción robusta de la libertad de elección. El sujeto no es determinado por los contenidos que elige, sino que se determina a sí mismo en ellos. En efecto, el sujeto puede resolverse por sus determinaciones, porque ellas son las suyas propias, es decir, porque son modificaciones de su propia subjetividad. Por esta razón, el sujeto siente dolor y no solamente lo observa: el dolor que siente es ya desde el vamos y como tal su propio dolor. Hegel identifica así la libertad práctica con la libertad trascendental. Cuando, por un acto de reflexión, el sujeto toma distancia respecto de sus sentimientos, es decir, de las 
afecciones que son ya explícitamente suyas, lo que está haciendo no es tomar distancia de lo externo a él; se trata allí, por el contrario, de una auto-escisión de la subjetividad misma. De este modo, las determinaciones no se relacionan con el sujeto como si fueran algo en sí mismo; en esa medida, no lo determinan como una cosa del mundo externo mueve a otra. Ciertamente elegimos siempre un contenido determinado, de la misma manera que siempre conocemos un objeto determinado. Pero en forma análoga a como para Hegel el mundo que el sujeto conoce no se le impone, sino que es el sujeto mismo el que puede comprenderlo en la medida en que modifica activamente las determinaciones de los objetos, el sujeto que se decide o resuelve por uno de sus impulsos no es determinado por el contenido de ese impulso, sino que es la propia autoconciencia subjetiva la que se determina y singulariza a sí misma en él.

\section{La libertad de autodeterminación: principio rector de la vida social, económica y política}

Aunque Hegel suscribe una concepción robusta de la capacidad de elegir no considera, sin embargo, que ella sea la verdadera libertad. La imposibilidad de satisfacerse a sí mismo en la búsqueda de la satisfacción de los múltiples impulsos espontáneos deriva en un proceso al infinito por el que el sujeto decide elaborar un plan estratégico, una selección inteligente de todos los impulsos que cree poder satisfacer. Este plan no es sino el ideal de la felicidad. Pero el ideal de la felicidad se basa en una resignación: para alcanzarlo, al sujeto no le queda más que sacrificar aquellos impulsos que no puede satisfacer. Esta insatisfacción y el intento renovado de superarla conducen a un nuevo proceso al infinito, a saber: el de la búsqueda incesante de la satisfacción general que siempre se escapa. Cuando cae en la cuenta de que en realidad no es ni solamente un conjunto de impulsos ni solamente la capacidad de elegirlos, de modo que no deben ser los impulsos los que constituyen el criterio de elección y acción del sujeto ni la mera capacidad formal de elegirlos, el sujeto toma conciencia de que en realidad es ambos: deseos e impulsos y capacidad de elegirlos. La subjetividad humana está siempre encarnada en un determinado cuerpo, con un determinado conjunto de impulsos y deseos, un determinado carácter y características, viviendo en un período histórico y una sociedad determinados, pero a pesar de ello es siempre capaz de resolverse por ese statu quo o de no hacerlo. La idea clave y novedosa que Hegel propone en este respecto es que es enteramente esencial a la libertad que el ser humano conciba el hecho que puede elegir sus propias determinaciones como su auténtica naturaleza. Es esta forma de autocomprensión lo que supera finalmente el estadio general del "mero" libre albedrío y transforma a la sola capacidad de elegir las propias determinaciones en la verdadera libertad, en la libertad efectivamente [wirklich] libre.

Cuando el saber de la idea -es decir, del saber de los seres humanos que su esencia, fin y objeto es la libertad- es especulativo, esta idea es ella misma como tal la realidad efectiva de los mismos, no que por ello los seres humanos la tengan, sino que la son. [...] Este querer la libertad ya no es más un impulso que exige su satisfacción, sino que es el carácter, es decir, la conciencia espiritual que se ha convertido en ser no-impulsivo [das zum trieblosen Sein gewordene geistige Bewußtsein]. (Hegel, 1992, p. 477 [Enz §482 Anm.]) [NB: Las cursivas son nuestras, H.F.]. 
Llegado a este estadio de autoconocimiento, la meta final de la vida interpersonal de los seres humanos en cuanto seres efectivamente libres pasa a ser que cada uno de ellos conserve la capacidad de ejercer su libertad respecto de sus propias determinaciones. El sistema de contenidos que el sujeto debe elegir es el que ofrece la condición de posibilidad para que obre según su esencia, es decir, es el orden que permite que cada sujeto permanezca siempre capaz de elegir cómo determinarse. Las estructuras de interrelación personal que Hegel desarrolla en su filosofía del derecho no son sino las que constituyen el marco general de ejercicio de la libertad de cada sujeto. Un sistema semejante de contenidos es entonces la manifestación o realización de la libertad humana. Si, por el contrario, el orden que los sujetos eligen no permite el ejercicio de la libertad de cada uno de ellos, dicho orden no es la manifestación o realización de su libertad y, en esa medida, ejerce violencia sobre los sujetos que viven bajo el mismo. El orden social no debe para Hegel santificar un modo concreto y específico de vida humana. El espíritu humano se define justamente por la superación de la naturaleza. La organización social y política deseable no es así aquella que promueve y defiende un tipo particular de humanidad, sino la que garantiza que los sujetos puedan elegir el tipo de humanidad que consideren en cada caso el adecuado para ellos. Para Hegel, es menos relevante qué elija el sujeto que el que pueda realmente elegirlo. A esto es justamente a lo que Hegel se refiere cuando sostiene que la libertad debe elegirse a sí misma como contenido y meta (Hegel, 1992, pp. 466 [Enz §469], 475-476 [Enz §§480-482]; Hegel, 2009, pp. 35 [§10], 41-42 [§§21-22]). La organización social y política adecuada es, pues, en cierto sentido, formal, dado que señala más bien negativamente lo que cada sujeto está obligado a acatar en su relación con los demás. Lo que el sujeto debe elegir es un orden concreto y determinado, pero el sentido y objeto de ese orden es que permita que todos los sujetos permanezcan siempre capaces de elegir de qué manera determinarse. Hegel rechaza la idea de un derecho natural derivable de que el sujeto tenga tales o cuales determinaciones y deba por ello respetarlas como si se tratara de un orden fijo de Ideas platónicas. Para Hegel, el espíritu humano consiste en sobreponerse a la naturaleza ejerciendo la capacidad de modificarla o negarla. Qué es lo que el ser humano haga con su libre albedrío viene dado por lo que decida hacer. El sistema material de contenidos que debe elegir en sus relaciones intersubjetivas es el que ofrece la posibilidad para que cada ser humano realice su propio proyecto personal. En la filosofía política de Hegel no se trata propiamente del contenido de las acciones en sus relaciones mutuas, sino más bien de que esas acciones permitan que todos los individuos logren desarrollar su capacidad de actuar según su propia decisión. En cuanto libre, el ser humano es un proyecto abierto, no una suma de cualidades naturales y de facultades a ser actualizadas. El orden social justo es así aquel que promueve y garantiza la formación e interacción de agentes humanos autónomos. Ciertamente Hegel hubiera estado de acuerdo con aquella frase que la novelista Evelyn Hall puso en boca de Voltaire: "No estoy de acuerdo con lo que Ud. dice, pero defenderé con mi vida su derecho a decirlo" (Tallentyre, 1906, p. 199).

Ahora bien, respecto de cada sujeto singular, las condiciones y circunstancias naturales, internas y externas, en las que le toca en cada caso vivir ofrecen una barrera que, aun en el marco del orden social que más permite el ejercicio de la libertad, resulta, en última instancia, 
infranqueable. La libertad no puede ser enteramente realizada en la relación de los sujetos con su corporeidad y carácter, con los demás sujetos y con el mundo en su constitución dada. En el marco de la interacción social, esto es, en el marco de lo que Hegel denomina "espíritu objetivo", la autodeterminación o autonomía del individuo permanece siempre, después de todo, una meta y una aspiración, en parte realizada, en parte nunca del todo realidad. La Historia Universal es por esto el plano de una mala infinitud, un proceso al infinito de logros y fracasos de la aspiración humana a la autonomía y la autodeterminación. La instauración del orden social más justo no es capaz de eliminar nunca del todo el crimen y las injusticias, como tampoco es capaz de evitar la contingencia y el azar de la Naturaleza, la cual puede traer consigo -por ejemplo, bajo la forma de catástrofes naturales- retrocesos en la realización de la libertad humana. Pero incluso al interior de la organización social configurada por el propio sujeto, la interacción de los múltiples sujetos singulares con sus intereses particulares - Hegel llama a esto “el sistema de las necesidades" (Hegel, 2009, pp. 165-174 [§§189-208])- genera inevitablemente la riqueza de algunos y la pobreza de otros.

En el plano específico de la singularidad, pues, lo otro de cada sujeto significa una alteridad en último análisis irreductible. En cuanto agente singular en un mundo de entidades singulares -el propio cuerpo, las cosas físicas y los demás sujetos-, la autoconciencia humana no puede configurar a lo otro de sí enteramente según el principio de la autodeterminación que define su esencia. De este modo, para Hegel la configuración del mundo de acuerdo a esa autonomía solo puede tener lugar en los productos culturales, en concreto, en el arte, la religión y la filosofía. Esta tesis puede resultar a primera vista sorprendente, porque parecería que es en el plano de la organización práctica de las relaciones intersubjetivas donde el sujeto tiene poder de modificar y configurar la constitución del mundo, y no en la actividad teórica de conocimiento, la cual estaría, por el contrario, determinada por los objetos que el sujeto conoce. Sin embargo, Hegel concibe a las cosas aparentemente externas como conceptos al interior de la teoría general del mundo que el sujeto en cada caso elabora. De este modo, los productos culturales que Hegel denomina "espíritu absoluto" no son sino las diferentes cosmovisiones que el propio sujeto configura para interpretar el mundo. Es en la activa elaboración de estas cosmovisiones como el sujeto puede poner plenamente en práctica su autonomía, en la exacta medida en que su teoría del mundo manifiesta su propia esencia, es decir, que lo que aparentemente determina su pensamiento como una cosa es, en realidad, una instancia o producto del propio pensamiento, una autodeterminación del mismo. La tesis más precisa de Hegel en este respecto es que hasta tanto la cosmovisión del sujeto no contenga en sí misma el que ella se trata efectivamente de una teoría del sujeto -y no un conjunto de cosas que se le imponen-, el sujeto mismo no puede ser todavía efectivamente libre. La actividad más relevante en el proceso de liberación del sujeto humano no es para Hegel, pues, la modificación de las formas de organización jurídica, socio-económica y política, sino la modificación del modo como el sujeto se entiende a sí mismo y, desde esa forma de autoconcepción, concibe lo que lo rodea. Hegel ve en las formas jurídicas, socio-económicas y políticas meros corolarios prácticos de las diferentes formas de autoconcepción del espíritu humano. En esta misma medida, considera que no es posible una revolución política sin una anterior reforma en el pensamiento, y remite en este 
contexto a la Reforma protestante (Hegel, 1970b, pp. 504-505). A sus ojos, el ideario y las implicancias prácticas de la Revolución Francesa no lograron tomar cuerpo en los países del Sur de Europa, como España e Italia, justamente porque estos países no habían abrazado antes el Protestantismo: "Napoleón fue tan poco capaz de forzar a España a la libertad como Felipe II lo había sido de forzar a Holanda a la servidumbre” (1970b, p. 535). La Reforma, que Hegel describe como "el sol que todo lo transfigura" (1970b, p. 491), emana del principio de la libertad; surge de la incorporación de ese principio al ámbito específico del pensamiento. La tesis que más que ninguna otra hace del cristianismo la "religión absoluta", es decir, la forma más acabada de la cosmovisión del pensar figurativo y metafórico propio de la religión, es para Hegel, según se adelantó, la de la Encarnación de Cristo. En el discurso simbólico de la religión, la tesis que Dios se hace hombre significa que el hombre es sagrado. La noción de que cada ser humano tiene en cuanto tal un valor y una dignidad infinitas es para Hegel un principio teórico de una importancia inmensa, ya que contiene el fundamento que debe vertebrar todas las relaciones humanas y, con ellas, el orden jurídico, económico y estatal. Resulta ahora más fácil entender aquella afirmación de Hegel mencionada más arriba que la revolución política no puede ocurrir si no hay antes una reforma del ánimo: esta reforma es, en primer lugar, la de la religión en general, en cuanto que, mediante la idea cristiana de la Encarnación de Dios, llega a declarar, siglos antes de la "Declaración de los derechos del hombre y del ciudadano" por la Asamblea Nacional Constituyente en la Revolución Francesa, el carácter sagrado de cada ser humano independientemente de su origen, clase social o nación.

Si bien la cosmovisión específica de la religión es un peldaño necesario en el proceso de autoconocimiento del sujeto humano, para Hegel es recién el pensamiento inferencial de la filosofía el que permite interpretar el universo de modo que su comprensión contenga explícitamente la autocomprensión de la subjetividad humana como autónoma. Un lugar común de la autocomprensión cultural de los países anglosajones ha sido vincular la tradición democrática en el plano político con el empirismo en los planos científico y filosófico. En efecto, autores como, por ejemplo, Bertrand Russell, Gilbert Ryle o Karl Popper buscaron fundamentar el supuesto vínculo entre empirismo y democracia, así como, en contrapartida, el supuesto vínculo entre la tradición racionalista continental y una propensión al autoritarismo y a las formas estatales antiliberales. En forma diametralmente opuesta a esta lectura, Hegel considera que es justamente la autoconcepción de la racionalidad humana como de suyo formal y la correlativa concepción del mundo como un ámbito extrínseco que se le impone a la razón subjetiva como un hecho bruto a través de sus impresiones sensibles lo que favorece un deficiente conocimiento de la propia dignidad y libertad del sujeto humano y, en esa medida, lo que ofrece la condición de posibilidad para formas de organización social y política que no respetan esa dignidad y libertad.

El principal problema que plantea la libertad desde un punto de vista filosófico radica en el conflicto entre el concepto de causa absoluta o incausada y el de necesidad o determinismo que rige las relaciones de las cosas del universo físico. ¿Cómo podrían las acciones humanas resultar de una causa que las provoca enteramente a partir de sí, sin ser ella misma efecto de 
una causa anterior? Semejante causa debería estar fuera del plexo de relaciones causales, dado que, de lo contrario, ella sería a su vez efecto de una causa y, por tanto, estaría determinada por ella a obrar como lo hace, pero, a pesar de esto, debería al mismo tiempo formar parte también de ese plexo para poder causar efectos al interior de él. Kant expuso de manera concisa este problema en la Crítica de la razón pura bajo la forma de la tercera de las antinomias de la razón pura (Kant, 1998, pp. 548-554 [KrV, A 444-451/B 472-479]). El modo tradicional como a lo largo de los siglos se ha intentado defender la tesis de la libertad humana en un mundo de cosas regidas exhaustivamente por la causalidad ha sido apelando a alguna forma de dualismo ontológico: el sujeto humano estaría en condiciones de iniciar una serie causal completamente nueva e impredecible dentro del conjunto total de procesos causales, porque no sería él mismo una cosa más entre las cosas que componen ese conjunto, sino una entidad perteneciente a otro dominio ontológico específicamente diferente, a saber: por así llamarlo, al "mundo de los espíritus". Sin embargo, aun perteneciendo a otro universo, el sujeto humano debería, no obstante, estar vinculado también a este universo físico, pues si no lo estuviera no podría influir de modo alguno en él. Cómo concebir una constitución ontológica tan curiosa ha sido desde siempre el talón de Aquiles de los defensores de la libertad personal. Para salvar la libertad, hasta el propio Kant no tuvo más remedio que recurrir a una forma sui generis de dualismo, a saber: a la de fenómeno y cosa en sí, según la cual el sujeto, en cuanto sujeto empírico, está determinado en su acción como el resto de las cosas empíricas, pero podría ser libre en cuanto cosa en sí o noúmeno (Kant, 1998, p. 621 [KrV, A 533/B 561], 629-630 [KrV, A 543-544/B 571-572]). El dualismo ontológico -incluso el kantiano- parece, sin embargo, ajeno al Zeitgeist contemporáneo. La concepción de la conciencia como un átomo anímico, tal como lo denominó Nietzsche (Nietzsche, 1988, pp. 26-27 [\$12]), es decir, como la unidad ontológica mínima de un universo enteramente diferente del universo físico que evidentemente habitamos, no parece, en efecto, poder ser conciliada con la cosmovisión de las ciencias naturales, la cual parece compaginarse mejor con un monismo materialista o fisicalista.

En este paisaje filosófico, el idealismo absoluto de Hegel viene a ofrecer una consistente alternativa al empirismo. Para Hegel, el contenido de las acciones humanas es siempre una determinación de las propias acciones, no una cosa que actúa sobre ellas otorgándoles su determinación, es decir, determinándolas. Es, pues, el contenido mismo de la acción y no el mero hecho de que la acción tenga un contenido lo que puede ser acorde o contrario a la libertad. A ojos de Hegel, la verdadera coacción sobre el individuo tiene lugar únicamente en el plano del contenido o determinidad de sus acciones y no por el solo hecho de que ellas sean acciones. Como tales, estas están integradas siempre en el conjunto total de eventos del universo físico, es decir, están vinculadas causalmente con las acciones de todos los otros entes del mundo. La circunstancia de que cada individuo forme necesariamente parte de una totalidad dentro de la cual interactúa con los demás agentes, sean estos conscientes o inconscientes, no debe ser el núcleo a partir del cual se elabora una teoría de la libertad. La verdadera libertad no reside para Hegel, como lo hace para la teoría liberal clásica, en la ausencia de obstáculos para la acción del individuo, sin consideración de cuáles sean las motivaciones materiales de esa acción. El fin 
último de la interacción social no debe ser la satisfacción de las necesidades de cada individuo, sino el efectivo ejercicio de su capacidad de elegir sus propias determinaciones. En esta medida, es la ignorancia o conciencia deficiente de que la esencia del agente humano es su capacidad de autodeterminación y autonomía lo que constituye la fuente última de toda servidumbre en los planos social, económico y político.

\section{Individuo, sociedad y Estado en la teoría política de Hegel}

Como se expuso en el primer apartado de este artículo, no pocas veces ha sido dirigida contra Hegel la crítica que en su concepción de la sociedad y el Estado los individuos son considerados como entidades sin valor y dignidad propias. Sin embargo, Hegel le otorga al individuo un rol fundamental y fundacional: su valor es “absoluto" y, en esa medida, debe constituir el principio rector de la constitución de todo el edificio social y estatal. La fuente de ese valor y dignidad no es sino la libertad. A diferencia de las cosas inanimadas y de los animales, el agente humano puede elegir sus propias determinaciones; estas no lo determinan a ser forzosamente tal o cual ente particular, sino que el ser humano puede decidir negar parcialmente las determinaciones que recibe de la Naturaleza, adoptar nuevas y de ese modo darse a partir de sí una segunda naturaleza -o incluso, eventualmente, negar todas sus determinaciones de una vez mediante el suicidio (Hegel, 1970a, p. 51 [\$5 Zus.]). Es justamente la libertad de autodeterminación lo que Hegel considera “infinito" y “divino" en el ser humano (Hegel, 2009, p. 38 [\$14], pp. 41-42 [§§21-22]). Esa libertad debe ser, pues, el fundamento último de la vida social y la organización estatal. El Estado es “divino", solo en la medida en que tiene como principio de su estructuración interna y como su objetivo principal promover y hacer en todo momento posible la autonomía de sus miembros:

La idea del Estado de la época moderna tiene la peculiaridad de que el Estado es la realización de la libertad no según el antojo subjetivo, sino según el concepto de la voluntad, es decir, según la universalidad y divinidad [Göttlichkeit] de la misma. [...] La esencia del nuevo Estado es que lo universal esté enlazado con la completa libertad de la particularidad y con el bienestar de los individuos; que, por tanto, el interés de la familia y de la sociedad civil debe concentrarse en el Estado, pero que, sin embargo, la universalidad de la meta no puede progresar sin el propio saber y querer de la particularidad, la cual tiene que conservar su derecho. Lo universal tiene, pues, que estar activado [betätigt sein], pero, por otro lado, la subjetividad debe desarrollarse en forma completa y viviente. (Hegel, 1970a, p. 407 [\$26o Zus.]).

La libertad como capacidad de autodeterminación no implica, sin embargo, que la meta del obrar deba ser entonces que cada individuo haga lo que quiera. En este punto, Hegel se distancia de la concepción liberal sobre la libertad individual, la vida económica y el Estado. El diagnóstico de Hegel es que si el ser humano toma como criterio de cada una de sus acciones el ejercicio mismo como tal de la capacidad de elección -Hegel llama a esto "arbitrio" [Willkür] y lo diferencia específicamente de la verdadera libertad [Freiheit] (Hegel, 1992, p. 474 [Enz §477]; 2009, pp. 
38-39 [§§15-17])-, el resultado paradójico es que lo que logra no es la libertad de todos, sino el caos de la colisión de los intereses particulares y la injusta concentración de recursos y poder en unos pocos individuos. El Estado es justamente la instancia que debe evitar que eso suceda; el sentido mismo del Estado es garantizar que todos y cada uno de los individuos que conforman la sociedad se convierta en un agente autónomo y pueda ejercer su capacidad de autodeterminación. En su teoría política, Hegel asume, pues, la idea principal de la teoría política liberal, pero precisamente para que esta idea sea efectivamente realizable y no permanezca un desideratum, un mero deber-ser, considera necesario corregir la tesis del "Estado mínimo", otorgándole al Estado una entidad más sólida, con una función más activa en la organización y gerencia de la vida económica y social de los individuos.

Cuando el criterio para la toma de decisiones es la libertad misma de tomarlas, la satisfacción de los deseos particulares de los individuos es lo que en la práctica se convierte en la meta material de sus acciones. La sociedad civil es el conjunto de individuos en la medida en que se interrelacionan para satisfacer sus necesidades y deseos privados. Pero la búsqueda del propio provecho y satisfacción individual, aunque contribuye de facto a la satisfacción del provecho y necesidades de los demás, conlleva por su propia naturaleza a conflictos de intereses y desequilibrios. La lógica del máximo provecho propio que rige la interrelación de los individuos en el marco de la sociedad civil no garantiza de suyo la satisfacción de las necesidades de todos los individuos que la conforman. Abandonado a sí mismo, el mercado, que es la dinámica de las relaciones interpersonales en la sociedad civil, propende al surgimiento de desequilibrios, excesos e injusticias (Winfield, 1991, pp. 127-128). Hegel ve en la concentración excesiva de riqueza en manos de unos pocos y la correlativa formación de una clase numerosa de indigentes, la plebe [Pöbel], una consecuencia natural de las relaciones sociales en las que los individuos rigen sus acciones por la sola búsqueda de la satisfacción de sus necesidades y deseos (Hegel, 2009, pp. 193-194 [§§243-245]). Si bien el mercado, como argumenta la teoría económica y política liberal, genera por su propia dinámica un cierto equilibrio y orden económico y social, Hegel considera que ese orden, por el carácter meramente formal de su génesis, no garantiza como tal que cada uno de los individuos que componen la sociedad acceda a los bienes necesarios -alimento, vivienda, salud, educación, cultura, etc.- para convertirse en un sujeto autónomo, es decir, para actualizar su esencia. Para lograr esto, las elecciones de los individuos no pueden orientarse exclusivamente por el interés de satisfacer sus necesidades y deseos privados, sino que deben también regirse por principios universales cuyo objetivo sea promover y asegurar la realización de la libertad de autodeterminación y autonomía de cada miembro de la sociedad. Esos principios universales no son sino las leyes y reglamentaciones del Estado, mediante las cuales, entre otras cosas, se regula la conducta de los individuos en el comercio y los negocios, se garantiza la educación a través de la implementación de la escolaridad obligatoria y se promueve la salud y el bienestar social (Luther, 2009, pp. 231-232).

La concepción liberal del Estado tiene a reducirlo a la sociedad civil. A ojos de Hegel, por el contrario, el Estado es una instancia con una especificidad propia: su sentido es la búsqueda del bien común como tal. El bien común no resulta necesariamente de la suma total de las acciones de los individuos destinadas a lograr su respectivo bien privado; precisamente por 
esto, el bien común debe ser un objetivo en sí mismo y debe haber una entidad específica que lo tenga como su meta. Pero esto no significa que el individuo deba por ello desaparecer bajo el Estado y sus intereses puedan ser desatendidos o negados por este. El Estado, tal como Hegel lo entiende, debe mediar entre lo particular y lo universal, entre el individuo y la sociedad, asumiendo en sí a ambos. En las sociedades pre-modernas, la comunidad no solo es lo primero -como lo es también, según Hegel, el Estado- sino que es, en rigor, lo único. El concepto universal de persona libre, la cual es como tal sujeto de derechos, está ausente en el mundo pre-moderno; en forma correlativa, el individuo no es reconocido allí en su individualidad por la organización social y política. En la sociedad moderna, en cambio, es la organización social y política misma la que está vertebrada en su propia estructura por el individuo que es por esencia libre y autónomo, individuo al cual, en esa medida, ella manifiesta y realiza. El individuo del que parten en la Edad Moderna Hobbes y Locke y, con ellos, la entera teoría liberal clásica, es para Hegel, sin embargo, una abstracción, el resultado de la absolutización de su particularidad contra el momento universal de la sociedad. Para Hegel, la individualidad es ontológicamente correlativa a la sociedad y el Estado. El ser humano no solo necesita de la vida en sociedad para cubrir sus necesidades básicas, desarrollar sus facultades y satisfacer sus distintos deseos, sino que deviene un individuo autónomo en la precisa medida en que se relaciona con otros seres humanos que lo reconocen como tal y a los que él también reconoce como iguales a sí. El individuo no es, pues, un punto de partida que pueda ser presupuesto de modo absoluto: en rigor, él mismo se va constituyendo como tal en la interacción social, mediante relaciones de mutuo reconocimiento. La eticidad antigua, que Hegel asume de hecho en su propia teoría política, debe ser, por su parte, corregida y complementada por el principio moderno de la individualidad (Neuhouser, 2000, pp. 34-35). La nueva eticidad que Hegel propone apunta a la reconciliación del individuo con la sociedad, pero también a la de la sociedad con el individuo.

[E]n el cumplimiento del deber, el individuo [Individuum] debe encontrar al mismo tiempo, de alguna manera, su propio interés, su satisfacción y su provecho[.] [...] El interés particular no debe en verdad ser dejado de lado ni mucho menos oprimido, sino que debe ser puesto en concordancia con lo universal; de ese modo, son conservados tanto el interés particular como lo universal. El individuo [Individuum], súbdito desde el punto de vista de sus deberes, encuentra como ciudadano, al cumplir con ellos, la protección de su persona y de su propiedad, la consideración de su bienestar particular y la satisfacción de su esencia sustancial[.] (Hegel, 2009, pp. 209-210 [\$261 Anm.]) [NB: Las cursivas son nuestras, H.F.].

\section{Referencias}

Adorno, T. W. (1986) (GS 10) Stichworte. En, R. Tiedemann (Ed.), Adorno. Gesammelte Schriften, vol. 10 (pp. 595-798). Suhrkamp.

Cassirer, E. (1946). The Myth of the State. Yale University Press. 
Feuerbach, L. (2006). Das Wesen des Christentums. En, W. Schuffenhauer y W. Harich (Eds.). Feuerbach. Gesammelte Werke, vol. 5 (pp. 1-454). Akademie Verlag.

Goodfield, E. (2017). Negating Negation. A Century of Revision in the Reception of Hegel's Political Philosophy. History of Political Thought, 38(2), 295-322.

Grattan-Guinness, I. (1992). Russell and Karl Popper: Their Personal Contacts. Russell: the Journal of Bertrand Russell Studies, 12(1), 3-18. https://doi.org/10.15173/russell.v12i1.1815

Haym, R. (1857). Hegel und seine Zeit. Gaertner.

Hegel, G. W. F. (1970a) (TWA 7). Grundlinien der Philosophie des Rechts. En, E. Moldenhauer y K. M. Michel (Eds.). Hegel. Werke in 20 Bänden, vol. 7 (pp. 11-512). Suhrkamp.

Hegel, G. W. F. (1970b) (TWA 12). Vorlesungen über die Philosophie der Geschichte. En, E. Moldenhauer y K. M. Michel (Eds.). Hegel. Werke in 20 Bänden, vol. 12 (pp. 11-540). Suhrkamp.

Hegel, G. W. F. (1970c) (TWA 16). Vorlesungen über die Philosophie der Religion I. En, E. Moldenhauer y K. M. Michel (Eds.). Hegel. Werke in 20 Bänden, vol. 16 (pp. 11-442). Suhrkamp.

Hegel, G. W. F. (1992) (GW 20). Enzyklopadie der philosophischen Wissenschaften im Grundrisse (1830). En, W. Bonsiepen y H.-Ch. Lucas (Eds.). Hegel. Gesammelte Werke, vol. 20. Meiner.

Hegel, G. W. F. (2009) (GW 14.1). Grundlinien der Philosophie des Rechts. En, K. Grotsch y E. WeisserLohmann. Hegel. Gesammelte Werke, vol. 14.1. Meiner.

Hegel, G. W. F. (2011) (GW 25.2). Vorlesungen über die Philosophie des subjektiven Geistes. Nachschrift zu dem Kolleg des Wintersemesters 1827/28 und sekundäre Überlieferung. En, Ch. J. Bauer (Ed.). Hegel. Gesammelte Werke, vol. 25.2. Meiner.

Hobhouse, L. T. (1918). The Metaphysical Theory of the State. George Allen \& Unwin.

Hook, S. (1936). From Hegel to Marx: Studies in the Intellectual Developmentof Karl Marx. Reynal \& Hitchcock.

Hook, S. (1965). Hegel Rehabilitated? Encounter, 24(1), 53-58.

Hürstel, S. (2010). Au nom de Hegel. Les juristes néo-hégéliens et la philosophie du droit de la République de Weimar au Troisième Reich. Presses universitaires de Rennes.

Internationaler Militärgerichtshof Nürnberg (Ed.) (1994). Der Nürnberger Prozess gegen die Hauptkriegsverbrecher vom 14. November 1945 bis 01. Oktober 1946. Vol. 5. Delphin.

Jouanjan, O. (1997). Les fossoyeurs de Hegel. Rénovation allemande du droit et néo-hégélianisme sous le IIle Reich. Droits: Revue française de théorie juridique, 25, 121-133.

Jouanjan, O. (2002). Communauté, race et rénovation allemande du droit. Karl Larenz, ou les errements de l'hégélianisme juridique sous le Troisième Reich. En, C. Colliot-Thélène y J.-F. Kervégan (Eds.). De la société à la sociologie (pp. 183-221). ENS Éditions.

Kant, I. (1998). Kritik der reinen Vernunft. Meiner.

Kiesewetter, H. (1974). Von Hegel zu Hitler. Eine Analyse der Hegelschen Machtstaatsideologie und der politischen Wirkungsgeschichte des Rechtshegelianismus. Hoffmann und Campe. 
Kiesewetter, H. (1995). Von Hegel zu Hitler. Die Verwirklichung einer totalitären Machtstaatstheorie in Deutschland (1815-1945). 2. völlig veränderte und erweiterte Auflage. Lang.

Luther, T. (2009). Hegels Critique of Modernity: Reconciling Individual Freedom and the Community. Lexington Books.

Maritain, J. (1936). Humanisme intégral. Aubier.

Maritain, J. (1951). Man and the State. The University of Chicago Press.

Marx, K. (1981) (MEW 1). Zur Kritik der Hegelschen Rechtsphilosophie. En, Institut für MarxismusLeninismus beim ZK der SED (Ed.), Marx \& Engels. Werke, vol. 1 (pp. 202-333). Dietz.

Neuhouser, F. (2000). Foundations of Hegel's Social Theory: Actualizing Freedom. Yale University Press.

Nicolin, G. (Ed.) (1970). Hegel in Berichten seiner Zeitgenossen. Meiner.

Nietzsche, F. (1988) (KSA 5). Jenseits von Gut und Böse. En, G. Colli y M. Montinari (Eds.). Nietzsche. Kritische Studienausgabe, vol. 5 (pp. 9-243). dtv/de Gruyter.

Popper, K. R. (1945). The open society and its enemies, vol. II: The high tide of prophecy: Hegel, Marx, and the aftermath. Routledge.

Popper, K. R. (1994). Alles Leben ist Problemlösen. Über Erkenntnis, Geschichte und Politik. Piper.

Sabine, G. H. (1932). Hegel's Political Philosophy. The Philosophical Review, 41(3), 261-282.

Sabine, G. H. (1937). A History of Political Theory. Oxford University Press.

Stewart, J. (2018). Hegel's Interpretation of the Religions of the World: The Logic of the Gods. Oxford University Press.

Tallentyre, S. G. (1906). The Friends of Voltaire. Smith, Elther \& co.

Winfield, R. D. (1991). Freedom and Modernity. State University of New York Press.

\section{AUTOR}

Héctor Ferreiro. Doctor en Filosofía por la Universidad Humboldt de Berlín. Investigador Independiente del Consejo Nacional de Investigaciones Científicas y Técnicas (CONICET) de Argentina. Ha realizado estancias de investigación posdoctoral en la Universidad Técnica de Berlín, la Universidad de Chicago, la Universidad de Heidelberg y la Universidad de Hagen. 